\title{
A Theoretical Application of Moral Risk in the Brazilian Energy Market
}

\author{
Sílvia Verônica Vilarinho Couto, Elder Mauricio Silva \\ Department of economics and international relations, UFSC, Florianopolis, Brazil \\ Email: elder0055@gmail.com
}

How to cite this paper: Couto, S.V.V. and Silva, E.M. (2017) A Theoretical Application of Moral Risk in the Brazilian Energy Market. Open Access Library Journal, 4: e3401.

https://doi.org/10.4236/oalib.1103401

Received: January 23, 2017

Accepted: March 20, 2017

Published: March 23, 2017

Copyright $\odot 2017$ by authors and Open Access Library Inc.

This work is licensed under the Creative Commons Attribution International License (CC BY 4.0).

http://creativecommons.org/licenses/by/4.0/ (c) $\underset{\mathrm{EY}}{\text { (i) Open Access }}$

\begin{abstract}
This paper aims to infer about the possible consequences of the existence of moral hazard in the Brazilian's electric sector for the final consumer. In 2013, the new regulatory framework in the Brazilian's electric sector was settled, which aims to encourage investment in quality and continuity of this services. Thus, the fees started to incorporate the costs related to the investments needed to maintain the quality and continuity of the service, which opens the door to the emergence of moral hazard. Moral risk has its origin in asymmetric information, which is a market failure that justifies the existence of economics regulations. In this sense, it is necessary to verify if the new regulatory framework, in fact, can encourage behavior that, per theory, should mitigate and its effects on the population. We found indices that the actual system adopted may drive the firms to explore a new regulatory system, harming the consumers at this process.
\end{abstract}

\section{Subject Areas}

Political Economy, Public Economics

\section{Keywords}

Asymmetric Information, Moral Hazard, Electricity Regulation

\section{Introduction}

Economic regulation aims to soften the so-called market failures, such as market power, information asymmetry, public goods, and externalities. Information asymmetry can be considered one of the main market failures and occurs when one of the parties involved in a transaction has relevant information that the other party does not know. The asymmetry of information can be easily verified in the agent-principal relationship. See, e.g., References [1] [2] and [3].

In the context of regulation, the asymmetry arises given the police maker's 
constraints to verify that all the decisions taken by the companies are in accordance with the pre-determined norms. Specifically, in the energy market, information asymmetry is related to the fact that the effectiveness effort to seek efficiency cannot be directly measured by a police maker.

The electric sector is a specific case of natural monopoly. Natural monopoly occurs when the cost of production makes a single producer more efficient than several producers. In this case, electricity, it is possible to see the distribution and transmission of energy as regional natural monopolies.

In this scenario, the regulation aims to contain possible abuses of the monopoly power that arise from the conflict between allocative efficiency and productive efficiency. One of the main tasks of the regulatory body is the choice of the tariff criterion, which is responsible for controlling price adjustments and the degree of price variation per different classes of consumers.

In 2013, Brazilian's law No. 12,783/2013 came into force, responsible for some changes in the regulatory framework of the Brazilian electric sector; previous one had been in force since 2004. The objective of this new regulation was to provide the conditions and security for the agents to make the necessary investments for continuity and quality of services provided. The concessionaires began to be remunerated by the tariff of service rendering, which includes operation and maintenance, and no longer by the sale of energy.

To do so, the tariffs began to incorporate the costs related to the investments necessary to maintain the quality and continuity of the service. The readjustment of the electric energy price began to consider the cost involved in the energy sector alone, will not use the general price index of the economy, as was in the previous regulations system.

However, a risk associated with this new regulatory framework is the possibility that the agents do not try to reduce their costs, increasing their remuneration and raising the tariff for the final consumer. That is, the new regulatory framework of the Brazilian electric market leaves leverage for the occurrence of moral hazard.

In this sense, the objective of the present study is to verify the possible consequences of the existence of moral hazard in the Brazilian's electric sector for the final consumer, considering the changes of the new regulatory framework of 2013. For that, we use the moral hazard model presented by [4] to simulate different economic scenarios with help of one macroeconomic agent based model.

The argument of the policy maker to support this new regulatory system was the necessity to improve the infrastructure investment. This work uses the moral hazard to check what will be the cost for society, that is, what could happen to the other sectors of the economy with this new framework; and compare with the others pos-sible regulatory systems.

In addition to this introduction, the literature on information asymmetry and moral hazard is briefly presented in the second section, followed by the model used to carry out the simulations, as well as their results, and some conclusive comments. 


\section{Theoretical Aspects}

The relationship between agent-principal can be observed in different economic contexts and with different implications. Reference [5] see as the common element that can be observed in all cases where there are two actors. One of them, the so-called agent, chooses an action from several possible alternatives. The other one, called the principal, in a simplified form, determines a rule that specifies the rate that the agent must pay when opting for a certain action as a function of the result observed by the principal.

However, the agent-principal relationship is jeopardized when there is uncertainty, more specifically when the available information is different for the participants. Reference [5] highlights two cases when the agent's action is not directly observed by the principal and when the agent's action does not entirely determine the outcome. The principal case the principal can infer the actions of the agent from the results; in the second case, in which the result is a random variable whose distribution depends on the action taken.

The asymmetry of information arises when one of the parties involved in a transaction has relevant information that the other party does not know. This is, see [4], the impossibility of observing and including all the individual actions of the parties involved in the transaction, contract. It is possible to divide the problem of asymmetry into two types: (i) moral hazard; and (ii) adverse selection.

Adverse selection is the problem that occurs when the agent makes some observation that the principal did not do before the transaction occur. Reference [6] says if the principal can observe the behavior of the agent or the implications of this decision will depend on the type of agent. It follows from the premise that there are certain characteristics in the production process that depend on the type of agent and principal is not able to make that distinction between the different types of agents.

Although widely applied in the context of insurance, adverse selection also has quite a few applications in the context of regulation. As noted by [6], the regulation of a public monopoly, considering economic efficiency, determines the price charged for the service must be equal to its marginal cost, and the fixed cost is covered by the regulators through of subsidies. If the regular has budgetary restrictions and cannot offer the subsidy, then the price would be equal to the average cost. In both cases the assumption is made that the regulator knows the cost function of the regulated as well as the regulation itself. This is not a realistic assumption, since firms have better information about their production than the regulator.

For [6] moral hazard arises when the agents' actions cannot be verified, or when the agent receives private information after the transaction. That is, at the time of the transaction, both agent and principal have the same set of information, but the principal cannot verify or control the agent's efforts perfectly after the transaction is signed.

One way to solve moral hazard would be by monitoring agents' actions. In the case of complete monitoring, all information collected would be part of the con- 
tract that would penalize the agent's dysfunctional behavior and the solution in this case would be optimal. However, as [4] points out, complete monitoring is impossible to achieve, or it can be so costly that it becomes a prohibitive expenditure. Thus, it is necessary to incorporate the presence of asymmetric information in contracts, transactions, relationships.

Reference [4] states that any additional information, provided it is valid, can be used to improve a contract. This additional information system can arise using secondary sources of information about agents or the state of nature. Other variables, observed by both the agent and the principal, can also be used as an informative sign of agent action. Finally, the author points out that in long-term contracts, in which a situation is repeated several times, the dysfunctional behavior of agents is revealed more precisely, which tends to reduce the problem of moral hazard.

Regulation is also used to mitigate moral hazard. As highlighted by [7], even with a deregulation movement observed in recent years, there are historically regulated sectors. These sectors are natural monopolies, such as the distribution of electricity, water, natural gas, among others. Regulation is traditional in these sectors and aims to stimulate efficient production, guaranteeing the regulated company the coverage of its costs and at the same time restricting its market power, preventing excessive charges to the final consumer.

However, as [8] points out, the contracts are flawed. In this sense, the regulated company can use information asymmetry in its favor, since the regulator does not have complete information about the reality faced by the regulated firm. According to [9], this asymmetry of information allows the regulated company to increase its profit or other target of interest, thus damaging the final consumer.

\section{Model}

To simulate the Brazilian energy market, we will assume the firms will always try to maximize their profit, even when that means they will use privileged information against the police makers. The government can only decide what the general rule to apply to the market, it is, after decide what type the regulation the market will settled nothing else will be done by the government.

To represents the regulatory framework of the Brazilian energy market with the presence of moral hazard, that is, considering that the companies that offer electricity are subject to government supervision could take advantage of a failure in the supervision to appropriate a higher amount of profit. In this case the agent and the principal do not enjoy the same set of information, i.e., there is asymmetry of information. It is possible to use the equations proposed by [4] to guide the model:

$$
x=x_{a}, \theta,
$$

in which, for this application, $x$ represents the results perceived by the electric power companies, given the uncertainties of the nature $\theta$ and given an action a. In Brazil, different from several countries, the supply of electricity depends on 
an exogenous event, that is: the amount of rainfall received by the country during the year. This dependence on the rainfall regime occurs because more than $90 \%$ of the energy produced in Brazil is produced through hydroelectric plants. Thus, different values of $\theta$ will be simulated, to verify how the results behave in scenarios with different levels of shocks in the environment.

In this way, as if it were an insurance, the government could impose a limit for the increases in the electric energy tariff. Like what happened with the old Brazilian energy regulatory framework. A second possibility is that the government does not regulate the market and allow competition between electric power companies and the supply of energy with a free price. A final option would be the government regulates the companies in a way to allow readjustments according the costs perceived by the companies themselves. For example, in the first situation, if the increase in the general level price is $10 \%$ in a year, the maximum that electricity companies could raise their tariffs would be $10 \%$ in the following year. In the latter case, if the energy companies showed to the government that they suffered a cost increase of $20 \%$, the contract would allow companies to increase their tariffs by the maximum of $20 \%$, even with the general price level having grown by only by half of that. We use the latter case is used to simulate the effects of the new regulatory framework.

The value of a is known to all: governments, and companies. It is the value of demand for electricity, so the profit of companies in this sector will depend on the demand for their product and the impact perceive at the environment. In sequence, it is presented how the simulations were constructed and which results was found.

\subsection{Simulating an Economy}

The virtual economy will be composed of residents, businesses, and the government. Residents may be workers or capitalists; workers will offer labor force and use their wages to consume goods; The capitalists are the owners of the companies, they make a profit and use this money to buy goods. Goods are produced by firms of consumer goods, which demand labor, energy, and capital goods. Capital goods companies demand work and energy. Energy companies demand natural resources, our $\theta$. The government will only play a regulatory role in the energy sector, being able to opt for one of the three regulatory profiles: (i) Regulation Type Costs; (ii) Regulation Type Price Index; and (iii) Regulation Type Free Market.

It is an agent based model, with mid-level agents, with three thousand workers, two hundred consumer companies, fifty capital goods companies, ten companies supplying electricity, and a government. The model is available online, built in free software, can be downloaded, and modified by the reader if you wish to perform simulations with other parameters.

The model and the data utilized in this work is available at: http://modelingcommons.org/account/models/712. All data utilized was generated in our model, which was built in an open source code. Further details of this 
simulated macroeconomics can be found in [10].

The GDP of this economy will be the sum of all that was produced in a period, the general price level will be the average prices of all the goods consumed in this economy in period $t$, and the price of energy will be measured as the average prices practiced by the electricity companies in a period.

The companies participate in a game that is mixed because they practice competition via price and quantity, Bertrand and Cournot's game, depending on whether their sales are above or below expected, that is, whether they are managing to hit the market or not. When your sales exceed your expectations and your prices are above the price index the company raises its quantity produced, if its price is below the price index it will raise its price and keep the quantity produced in summary:

$$
Y_{i, t}^{*}=\left\{\begin{array}{c}
Y_{i, t}+\left(-\delta_{i, t}\right) s e \delta_{i, t} \leq 0 e P_{i, t}>P_{t} \\
Y_{i, t}+\left(\delta_{i, t}\right) s e \delta_{i, t}>0 e P_{i, t}<P_{t}
\end{array} .\right.
$$

The $Y_{i, t}^{*}$ represents the production of a single firm in period $\mathrm{t}$, the sum of the output of all firms will be the GDP of this economy. Figure 1 shown a representation of how real GDP and energy consumption evolve, normalized here being $t_{0}=1$ for all series. The price rule guiding this economy is also similar, $\delta$, which appears in both the price and quantity equations, represents the production error, i.e., how much was the production error in the previous period, if the production coincided with the quantity demanded in each period then $\delta_{i, t}=0$.

$$
P_{i, t}= \begin{cases}P_{i, t} \times\left(1+\rho_{i, t}\right) s e \delta_{i, t} \leq 0 & e P_{i, t}>P_{t} \\ P_{i, t} \times\left(1-\rho_{i, t}\right) s e \delta_{i, t}>0 & e P_{i, t}<P_{t}\end{cases}
$$

In case of companies that produce capital goods and consumer goods, the value of $\rho_{i, t}$ is produced by a uniform distribution with support $(0 ; 0.10)$. For companies that supply electricity here will be attributed the environmental fac-

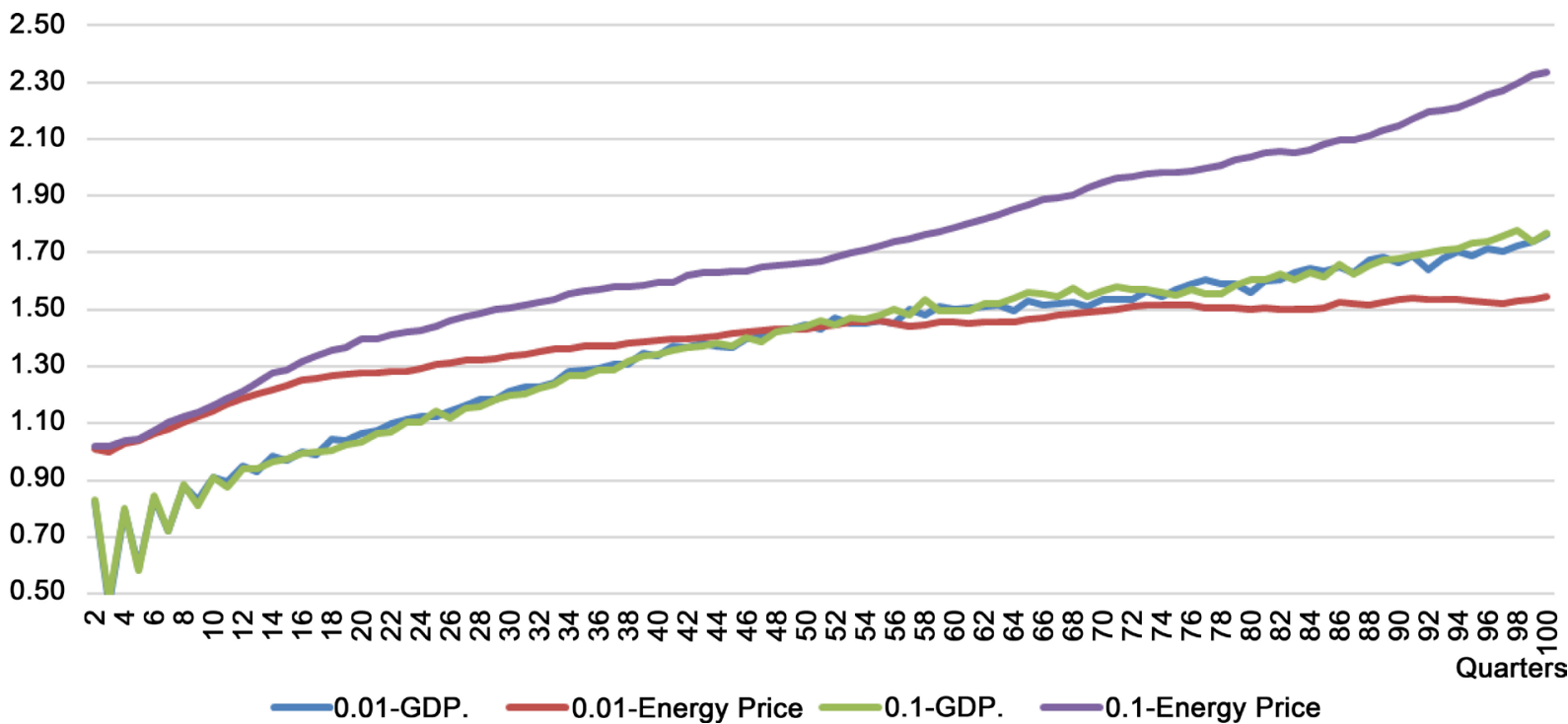

Figure 1. Energy price and the real GDP, values are an average of ten simulations for each value of rainfall shock: 0.01 and 0.10 
tor that represents the abundance or absence of rainfall. Thus, the support value for this distribution will be governed by $\theta$, so in the case of electric power companies we have: $(0 ; \theta)$.

\subsection{Environmental Shocks}

To analyze the environmental impact, we run simulations with 100 periods, representing one hundred quarters or twenty-five years; which would be the approximate time of a contract of an electric power company has with the government, that is, the time the company will be under a certain regulatory framework. At the beginning of the simulation a value for the environmental shock, $\theta$, is given; which a low value represents a good climatic condition that favor the production of electric and represents low production costs for the sector. The increase in environmental shocks meant severe shocks in the amount of the rainfall, which would lead to periods of low supply of raw material for electricity generation companies.

Table 1 presents a summary of what would happen to the prices practiced in the electricity sector considering the different regulatory profiles that the government can practice. With excellent climatic conditions, as shown in Table 1 in column $\theta=0.01$, the regulation via costs would reach the end of the period with the best value charged by the energy, however, with adverse scenarios the amount charged for this type of regulation would lead to the end of two times higher than the other types of regulation.

\subsection{Study of the Evolution of Prices for Different Regulatory Frameworks}

Detailing each regulatory framework; in the first case, which can be seen in Figure 2, considers that the government uses the cost perceived by electric power companies to authorize tariff increases. In this case, it does not use the general price index of the economy, but only the costs that impact the electric power sector and that are linked to the maintenance, quality, and continuity of services offered. This case, called Regulation Cost Type, is what represents the current Brazilian regulatory framework. Considering this type of regulation, it would be possible to verify the problem of information asymmetry, more specifically moral hazard. Companies could overestimate their costs to obtain additional gains when adjusting tariffs. With small impacts in the climatic conditions, low values of $\theta$, the increase of the price of electric energy does not undergo major changes, but as the climatic variations become more drastic, increases in $\theta$, the value

Table 1. Variation at the final price of energy for each type of regulation and for different shocks at the rainfall.

\begin{tabular}{cccccccccccc}
\hline Regulation/ $\theta$ & 0.01 & 0.02 & 0.03 & 0.04 & 0.05 & 0.06 & 0.07 & 0.08 & 0.09 & 0.1 \\
Costs & 1.13 & 1.30 & 1.48 & 1.61 & 1.86 & 2.07 & 2.37 & 2.80 & 3.17 & 3.60 \\
Free Market & 1.83 & 1.51 & 1.36 & 1.51 & 1.05 & 1.39 & 1.53 & 1.51 & 1.26 & 1.71 \\
General Price Index & 1.68 & 1.69 & 1.68 & 1.71 & 1.69 & 1.72 & 1.73 & 1.67 & 1.73 & 1.70 \\
\hline
\end{tabular}




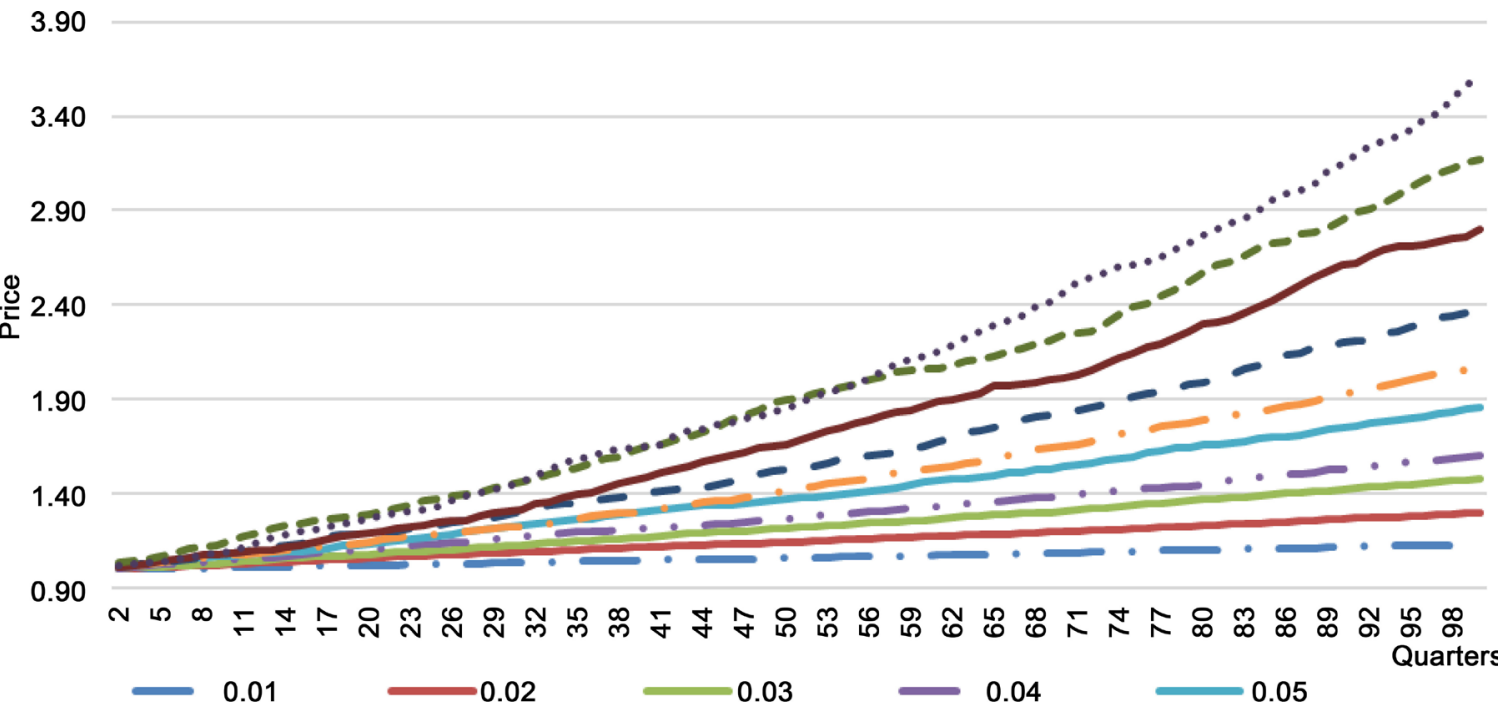

Figure 2. Energy price for Regulation Type Costs and different values of rainfall shocks. The 0.10 is the worst scenario in the environment and has the highest price of energy.

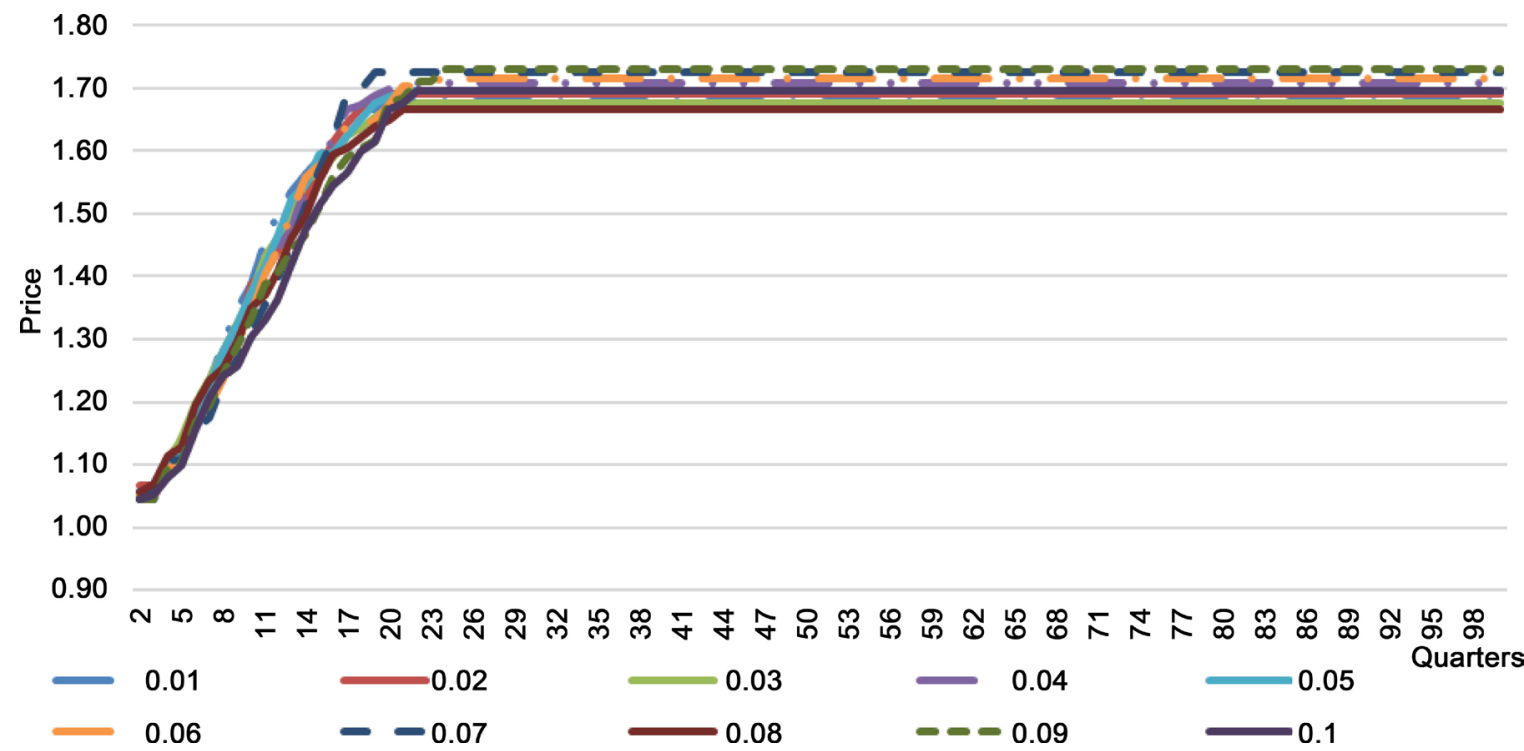

Figure 3. Energy price for Regulation Type Price Index and different values of rainfall shocks. After 20 quarters, five years, the prices converge, and even for many rainfalls shocks the energy's price stay close each other.

charged by the electric energy triggers.

When the government uses another rule to regulate the energy's price, such as a general price index, the result is different. Contrary to what happened in the previous case, prices did not diverge, even with different environmental impacts, at the end of the period the series of prices end up very close, as can be seen in Figure 3. Since the energy's prices can rise only to the general price level limit, the energy's companies ask the government the raise their tariffs. At first, the different climatic conditions provide some disturbances in the prices, but around the fifth year of contract the prices practiced approach and since then they continue next until the 25th year of the contract. 
The best situation for the consumer is the free market with good weather conditions. However, as can be seen in Figure 4, the free market prices are also very affected by the value of $\theta$, that is, the climatic conditions are transferred to the prices, in situations of adversity the energy's prices can rise rapidly. It is interesting to note that in this scenario we observe some temporary points of decrease in the energy value, something that does not occur in other simulations.

In all simulations, the economy stabilizes after a few years, there is neither population growth, nor capital or labor productivity changes, so that only shocks in the environment are capable of affect the economy. The fact that the Price Index Type Regulation stabilizes at some point reflects this. The economy finds a balance and the only point that still fluctuates is the energy costs, the production is stable, the prices practiced by the other sectors of the economy find a stable level of exchange, so that the energy sector starts to absorb resources from this economy.

In regulation type price, the government authorizes increases in energy's price when the general price index goes up. Then, when the price index is reduced, electricity companies do not reduce their prices, stabilizing them at the highest point authorized by the government, thus improving their relative position through the other participants of this economy.

The situation of the regulation cost type performs even worse, since it is the series with the most expensive energy offered in the analysis in question, considering $\theta=0.05$. Note that for the same $\theta=0.05$, see Table 2 , the price of energy in the free market regulation type at the end of the twenty-five years is almost half of the amount charged in the regulation type costs. This behavior can occur because companies ask for authorization to increase tariffs when their costs are impacted, but do not reduce when the situation is favorable. Then a new negative impact occurs, a new drought, a long period without rains, and the govern-

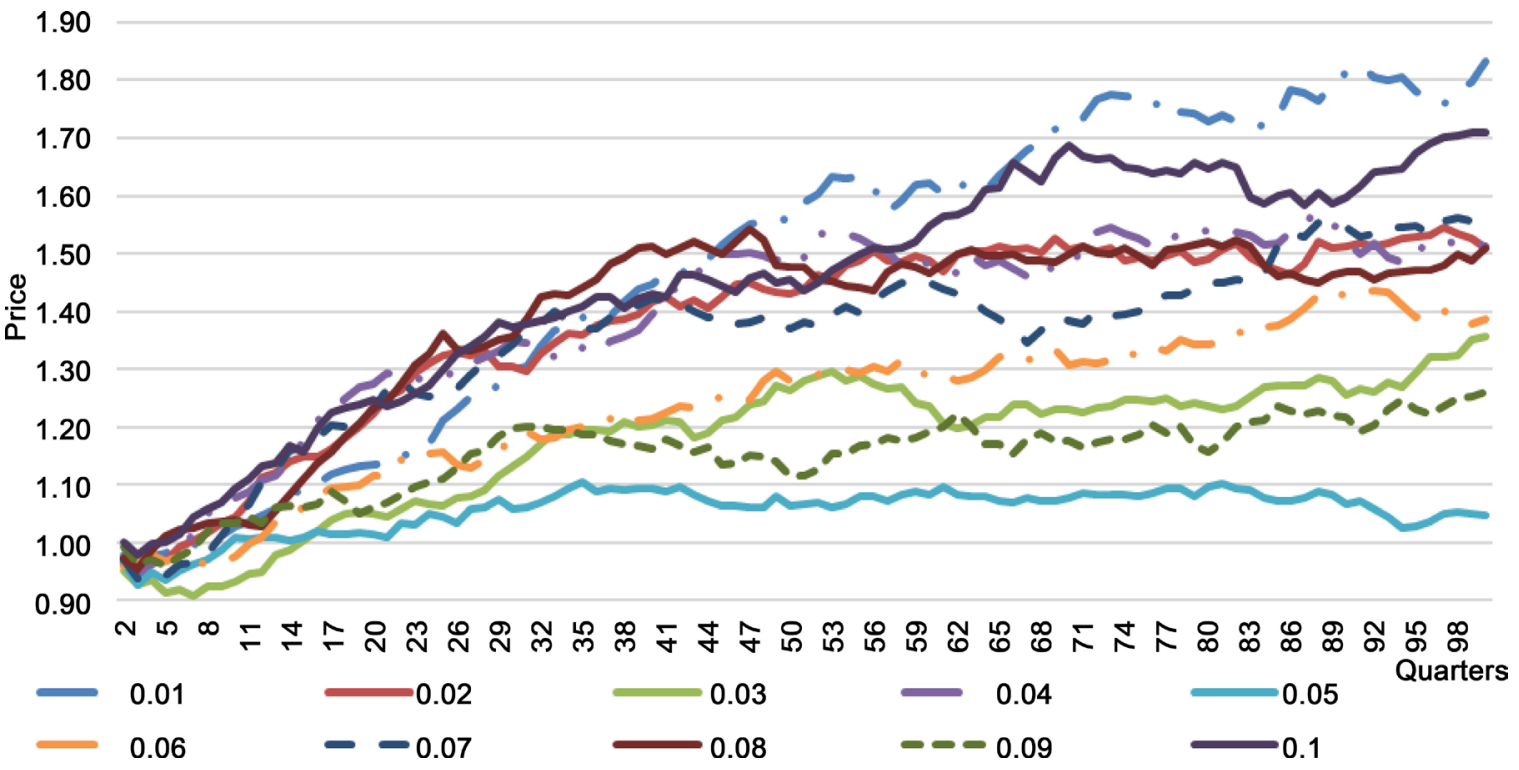

Figure 4. Energy price for regulation type: Free Market. Good environment conditions (rainfall shock $=0.01$ ) lead to a low price for energy at end of 25 years. 
Table 2. The results for energy price during the 100 quarters simulated with each type of regulations. Each result is an average of ten simulations.

\begin{tabular}{|c|c|c|c|c|c|c|c|c|c|c|}
\hline & \multicolumn{10}{|c|}{ Shocks at rainfall: } \\
\hline Period/Regulation & 0.01 & 0.02 & 0.03 & 0.04 & 0.05 & 0.06 & 0.07 & 0.08 & 0.09 & 0.1 \\
\hline \multicolumn{11}{|l|}{10} \\
\hline Costs & 1.01 & 1.03 & 1.04 & 1.05 & 1.07 & 1.07 & 1.08 & 1.09 & 1.15 & 1.10 \\
\hline Free Market & 1.03 & 1.05 & 0.93 & 1.08 & 1.01 & 0.98 & 1.04 & 1.04 & 1.03 & 1.09 \\
\hline Price Index & 1.39 & 1.39 & 1.37 & 1.36 & 1.38 & 1.34 & 1.31 & 1.35 & 1.33 & 1.30 \\
\hline \multicolumn{11}{|l|}{20} \\
\hline Costs & 1.02 & 1.06 & 1.08 & 1.11 & 1.13 & 1.15 & 1.19 & 1.20 & 1.29 & 1.28 \\
\hline Free Market & 1.14 & 1.22 & 1.05 & 1.27 & 1.01 & 1.12 & 1.23 & 1.23 & 1.06 & 1.25 \\
\hline Price Index & 1.68 & 1.69 & 1.67 & 1.70 & 1.69 & 1.67 & 1.73 & 1.65 & 1.68 & 1.67 \\
\hline \multicolumn{11}{|l|}{30} \\
\hline Costs & 1.04 & 1.09 & 1.13 & 1.17 & 1.22 & 1.22 & 1.29 & 1.31 & 1.45 & 1.44 \\
\hline Free Market & 1.30 & 1.30 & 1.13 & 1.35 & 1.06 & 1.18 & 1.34 & 1.36 & 1.20 & 1.37 \\
\hline Price Index & 1.68 & 1.69 & 1.68 & 1.71 & 1.69 & 1.72 & 1.73 & 1.67 & 1.73 & 1.70 \\
\hline \multicolumn{11}{|l|}{40} \\
\hline Costs & 1.05 & 1.12 & 1.17 & 1.22 & 1.31 & 1.31 & 1.41 & 1.49 & 1.65 & 1.65 \\
\hline Free Market & 1.45 & 1.42 & 1.20 & 1.40 & 1.09 & 1.21 & 1.42 & 1.51 & 1.16 & 1.43 \\
\hline Price Index & 1.68 & 1.69 & 1.68 & 1.71 & 1.69 & 1.72 & 1.73 & 1.67 & 1.73 & 1.70 \\
\hline \multicolumn{11}{|l|}{50} \\
\hline Costs & 1.06 & 1.14 & 1.22 & 1.27 & 1.37 & 1.42 & 1.53 & 1.66 & 1.90 & 1.85 \\
\hline Free Market & 1.56 & 1.43 & 1.26 & 1.51 & 1.06 & 1.28 & 1.37 & 1.48 & 1.12 & 1.46 \\
\hline Price Index & 1.68 & 1.69 & 1.68 & 1.71 & 1.69 & 1.72 & 1.73 & 1.67 & 1.73 & 1.70 \\
\hline \multicolumn{11}{|l|}{60} \\
\hline Costs & 1.07 & 1.17 & 1.26 & 1.33 & 1.46 & 1.53 & 1.66 & 1.87 & 2.06 & 2.13 \\
\hline Free Market & 1.62 & 1.49 & 1.24 & 1.48 & 1.08 & 1.29 & 1.45 & 1.47 & 1.19 & 1.55 \\
\hline Price Index & 1.68 & 1.69 & 1.68 & 1.71 & 1.69 & 1.72 & 1.73 & 1.67 & 1.73 & 1.70 \\
\hline \multicolumn{11}{|l|}{70} \\
\hline Costs & 1.09 & 1.20 & 1.31 & 1.39 & 1.54 & 1.65 & 1.83 & 2.01 & 2.25 & 2.46 \\
\hline Free Market & 1.72 & 1.51 & 1.23 & 1.48 & 1.08 & 1.31 & 1.38 & 1.50 & 1.18 & 1.69 \\
\hline Price Index & 1.68 & 1.69 & 1.68 & 1.71 & 1.69 & 1.72 & 1.73 & 1.67 & 1.73 & 1.70 \\
\hline \multicolumn{11}{|l|}{80} \\
\hline Costs & 1.10 & 1.23 & 1.37 & 1.45 & 1.66 & 1.79 & 1.99 & 2.30 & 2.57 & 2.77 \\
\hline Free Market & 1.73 & 1.49 & 1.24 & 1.54 & 1.10 & 1.34 & 1.45 & 1.52 & 1.16 & 1.65 \\
\hline Price Index & 1.68 & 1.69 & 1.68 & 1.71 & 1.69 & 1.72 & 1.73 & 1.67 & 1.73 & 1.70 \\
\hline \multicolumn{11}{|l|}{90} \\
\hline Costs & 1.12 & 1.27 & 1.42 & 1.53 & 1.75 & 1.93 & 2.20 & 2.61 & 2.85 & 3.15 \\
\hline Free Market & 1.81 & 1.51 & 1.26 & 1.52 & 1.07 & 1.43 & 1.54 & 1.47 & 1.22 & 1.60 \\
\hline Price Index & 1.68 & 1.69 & 1.68 & 1.71 & 1.69 & 1.72 & 1.73 & 1.67 & 1.73 & 1.70 \\
\hline \multicolumn{11}{|l|}{100} \\
\hline Costs & 1.13 & 1.30 & 1.48 & 1.61 & 1.86 & 2.07 & 2.37 & 2.80 & 3.17 & 3.60 \\
\hline Free Market & 1.83 & 1.51 & 1.36 & 1.51 & 1.05 & 1.39 & 1.53 & 1.51 & 1.26 & 1.71 \\
\hline Price Index & 1.68 & 1.69 & 1.68 & 1.71 & 1.69 & 1.72 & 1.73 & 1.67 & 1.73 & 1.70 \\
\hline
\end{tabular}


ment authorizes a new increase, a cascade effect that cumulatively penalizes the consumers.

\section{Discussion}

In 2013 Brazil adopted a new regulatory framework for the electric energy sector, a milestone that approaches what in this model we consider the Regulation Type Costs. The perceived costs by the electricity sector are passed on to consumers via the price of their tariffs. Part of this is already observed in the light bill, with successive readjustments during the subsequent years. The government's argument for such a practice is that with this regulation the electricity companies will have fewer risks, thus increasing their investments, increasing the quality of service provided.

Our analysis show it imply a higher impact to the last consumer, that is, the electricity sector absorbs wealth from other entities of this economy, making it an attractive business. However, it should be noted that consumers never benefit in this scenario. In Table 2, which shows the evolution of the price indices and energy prices for the different environmental scenarios; we can see that the Regulation Type Cost is the one that most penalizes the consumer, and other sectors of the economy.

The previous regulatory framework, in force until 2013, the Price Index Regulation, it is, energy companies can raise their prices up to the general price level of the economy. The simulations show that the general level of price stabilizes when the economy reaches level, nearly the fifth year of contract. Even if the electric companies ask for permission to raise their prices to the maximum possible in each period this situation is less onerous than the Regulation Type Costs.

We explain this behavior thru moral hazard. The government would need companies to take social welfare into account, not just their profit maximization, by calling for tariff increases. Moreover, under the new regulatory framework, companies must continuously seek to reduce their internal costs by investing in improvements in productivity to reduce the impact in other sectors of the economy.

The free market energy could be the best scenario in case of good patterns into the rainfall. But goes against the will of the government to provide more incentives to companies to invest. The risk to seek, providing energy in a competitive market, could restrain investment in the sector, which exactly what the police maker is trying to avoid. However, the regulation which uses the general price index of the economy could provide some security to investor if lowest cost.

\section{Conclusions}

In this work, we see the new policies implemented by the policy maker in Brazil may drive to a non-optimal condition. If the firms use their privileged position the others sectors of Brazilian economy will suffer, will occur transfer of re- 
sources to the energy sector. The argument of the policy maker at the time to implement the actual rule was to improve conditions for new investment in infrastructure, nevertheless we think this will be achieve through inhibitions of growth from others sectors.

This work considers as taken the proportion of hydraulic source of Brazilian matrix energy. For future works this scenario could be change. Once the rainfall fluctuation is the major source of instability in the system, addicting other sources of energy may drive to new challenges.

\section{Acknowledgements}

The authors gratefully acknowledge the CAPES (Coordenação de aperfeiçoamento de pessoal de nível superior-Brazil) for financial support.

\section{References}

[1] Ross, S.A. (1973) The Economic Theory of Agency: The Principal's Problem. The American Economic Review, 63, 134-139.

[2] Eisenhardt, K.M. (1989) Agency Theory: An Assessment and Review. Academy of Management Review, 14, 57-74.

[3] Fudenberg, D. Holmstrom, B. and Milgrom, P. (1990) Short-Term Contracts and Long-Term Agency Relationships. Journal of Economic Theory, 51, 1-31. https://doi.org/10.1016/0022-0531(90)90048-O

[4] Hölmstrom, B. (1979) Moral Hazard and Observability. The Bell Journal of Economics, 74-91. https://doi.org/10.2307/3003320

[5] Arrow, K.J. (1984) The Economics of Agency. Technical Report. Stanford University. Institute for Mathematical Studies in the Social Sciences Technical Report No. 451, 1-30.

[6] Macho-Stadler, I. and Pérez-Castrillo, J.D. (2001) An Introduction to the Economics of Information: Incentives and Contracts. Oxford University Press on Demand, 9-16.

[7] Joskow, P.L. (2008) Incentive Regulation and Its Application to Electricity Networks. Review of Network Economics, 9-26. https://doi.org/10.2202/1446-9022.1161

[8] Williamson, O.E. (1985) The Economic Intstitutions of Capitalism. Simon and Schuster, 47-56

[9] Laffont, J.-J. and Tirole, J. (1993) A Theory of Incentives in Regulation and Procurement. MIT Press, Cambridge, MA, 53-128.

[10] Assenza, T., Gatti, D.D. and Grazzini, J. (2015) Emergent Dynamics of a Macroeconomic Agent Based Model with Capital and Credit. Journal of Economic Dynamics and Control, 50, 5-28. https://doi.org/10.1016/j.jedc.2014.07.001 
Submit or recommend next manuscript to OALib Journal and we will provide best service for you:

- Publication frequency: Monthly

- 9 subject areas of science, technology and medicine

- Fair and rigorous peer-review system

- Fast publication process

- Article promotion in various social networking sites (LinkedIn, Facebook, Twitter, etc.)

- Maximum dissemination of your research work

Submit Your Paper Online: Click Here to Submit

Or Contact service@oalib.com 